\title{
Muscle morphology and metabolism in hypothyroid myopathy: effects of treatment
}

\author{
ALI A KHALEELI, K GOHIL, G MCPHAIL, JM ROUND, RHT EDWARDS \\ From the Department of Medicine, University College London, School of Medicine, London WC1E 6JJ
}

SUMMARY Needle biopsies from vastus lateralis in untreated hypothyroid patients with muscle weakness confirmed by quadriceps force measurements $(n=11)$ were repeated when the patients had taken L-thyroxine for a mean period of 9.2 months (range 5.3-13.3 months, $\mathrm{n}=8$ ) and had been continuously biochemically euthyroid for a mean period of 4.9 months (range 2-11 months). Biopsies were analysed biochemically for mitochondrial function. On light microscopy, histochemical examination, mean fibre areas and fibre percentages of type I and type II fibres were determined. Electronmicroscopy was also performed. Abnormalities on light microscopy occurred in eight patients of which type II fibre atrophy was the commonest and of the remainder two patients showed a myopathic electromyogram (EMG) and a raised plasma creatine kinase activity and one ultrastructural change on biopsy. After treatment resolution of pathological changes was often slow and half the patients had persistent abnormalities when rebiopsied.

The type I mean fibre area was significantly increased in the eight hypothyroid females $(p<0.05)$ and type II mean fibre areas tended to be low and in females this was significant $(p<0.05)$. After treatment the type I mean fibre area was significantly reduced $(p=0.05)$. The type II mean fibre area also tended to fall but this was not significant $(p>0.05)$. No change in the fibre percentages occurred.

A myopathic EMG, a raised plasma creatine kinase activity, ultrastructural changes and low mitochondrial enzyme activities on needle biopsy were other common findings and their significance is discussed.

Needle biopsy of skeletal muscle ${ }^{1}$ may be readily repeated, avoids the need for a general anaesthetic, potentially hazardous in hypothyroidism, and is ideal for studying the reversible nature of hypothyroid myopathy. Improved techniques for examining small quantities of muscle for histochemistry and mitochondrial function ${ }^{2}$ have offset its disadvantage of providing small samples of tissue.

Type I fibre predominance and selective atrophy of type II fibres in hypothyroid myopathy is well known $^{3}$ as is the presence of increased numbers of internal nuclei. ${ }^{4}$ Ultrastructural changes include accumulation of glycogen, ${ }^{5}$ abnormal mitochondria and lipid accumulations ${ }^{6}$ and in thyroidectomised animals hypertrophy and increased numbers of mitochondria in perinuclear and subsarcolemmal regions. $^{7}$

Type II fibre diameters have been found to be small. ${ }^{38}$ Type I fibre diameters were of normal size

Accepted for publication 22 December 1982 in McKeran's series ${ }^{3}$ but three untreated female hypothyroid patients reported by Wiles ${ }^{8}$ had large type I fibres. Using an electronic planimeter system mean fibre areas could be measured by drawing round individual fibres and this technique allowed greater precision particularly when the fibres were of irregular shape. 9

The aim of our study was to characterise abnormalities in histochemistry, electronmicroscopy, mitochondrial function and to measure mean fibre area and percentages of both type I and type II fibres in untreated hypothyroidism and to observe the effects of treatment on these abnormalities.

\section{Patients, material and methods}

PATIENTS

Eight women and three men patients, with both clinical and biochemical evidence of primary hypothyroidism were studied (Table 1). Their mean age was $61 \mathrm{yr}$ (range 51-71 yr). All had both general 
Table 1 Clinical, biochemical and endocrinological features of eleven untreated hypothyroid patients

\begin{tabular}{|c|c|c|c|c|}
\hline Patients & $\begin{array}{l}\text { Serum T4 }(\mathrm{nmol} / \mathrm{l}) \\
(N R=70-160)\end{array}$ & $\begin{array}{l}\text { Serum TSH }(I U / l) \\
(N R=0-4)\end{array}$ & $\begin{array}{l}\text { Plasma CK }(I U / l) \\
(N R=10-120)\end{array}$ & $E M G$ \\
\hline $\begin{array}{l}1 \\
2 \\
3 \\
4 \\
5 \\
6 \\
7 \\
8 \\
9^{*} \\
10 \\
11^{*} \\
\text { Mean } \\
\text { Median }\end{array}$ & $\begin{array}{r}<10 \\
<10 \\
<10 \\
<10 \\
17 \\
34 \\
17 \\
22 \\
<10 \\
63 \\
17 \\
-\quad 17\end{array}$ & $\begin{array}{r}>64 \\
>64 \\
23 \\
>64 \\
>64 \\
32 \\
>64 \\
53 \\
>64 \\
15 \\
>64 \\
- \\
>64\end{array}$ & $\begin{array}{r}4640 \\
639 \\
1399 \\
445 \\
87 \\
225 \\
130 \\
91 \\
877 \\
54 \\
553 \\
831 \\
445\end{array}$ & $\begin{array}{l}\text { Myopathic } \\
\text { Myopathic } \\
\text { Normal } \\
\text { Myopathic } \\
\text { Myopathic } \\
\text { Myopathic } \\
\text { Myopathic } \\
\text { Myopathic } \\
\text { Myopathic } \\
\text { Normal } \\
\text { Myopathic }\end{array}$ \\
\hline
\end{tabular}

*Indicates male sex.

Table 2 Effect of treatment on vastus lateralis histochemistry and mean fibre areas in hypothyroidism

\begin{tabular}{|c|c|c|c|}
\hline Histochemistry & $\begin{array}{l}\text { Hypothyroid } \\
(n=11)\end{array}$ & $\begin{array}{l}\text { Euthyroid } \\
(n=8)\end{array}$ & $\begin{array}{l}\text { Controls } \\
(n=13 M, n=11 F)\end{array}$ \\
\hline $\begin{array}{l}\text { Abnormality present } \\
\text { Type II fibre atrophy } \\
\text { Type I fibre predominance } \\
\text { Increased acid phosphatase } \\
\text { Large fibres } \\
\text { Central nuclei and ring fibres }\end{array}$ & $\begin{array}{l}8 \\
5 \\
3 \\
3 \\
2 \\
1\end{array}$ & $\begin{array}{l}4 \\
2 \\
0 \\
3 \\
0 \\
0\end{array}$ & $\begin{array}{l}\frac{0}{-} \\
- \\
-\end{array}$ \\
\hline $\begin{array}{c}\text { Mean fibre areas }( \pm S E M) \\
\text { Type I fibres-women } \\
\text { - men } \\
\text { Type II fibres-women } \\
\text { - men }\end{array}$ & $\begin{array}{l}5840^{*}(\mathrm{n}=8) \\
5770 \\
2580^{*}\left(\begin{array}{c}\mathrm{n}=3 \\
\mathrm{n}=8\end{array}\right) \\
3580 \quad(\mathrm{n}=3)\end{array}$ & $\left.\begin{array}{l}3830 \\
3290 \\
2010 \\
2200\end{array}\right\} \neq\left(\begin{array}{l}n=6) \\
n=2 \\
n=6 \\
(n=2)\end{array}\right.$ & $\begin{array}{l}3260 \pm 577 \\
6180 \pm 560 \\
3260 \pm 577 \\
6180 \pm 560\end{array}$ \\
\hline
\end{tabular}

${ }^{*} \mathrm{p}<0.05$ using Student's unpaired $t$ test.

$\dagger \mathrm{p}=0.05$ using Student's paired $t$ test.

$\mathrm{p}<0.05$ using Wilcoxon paired sign test.

$\ddagger \mathrm{p}=>0.05$ using both Wilcoxon paired sign test and Student's paired $t$ test.

and muscle symptoms of hypothyroidism and the mean duration of the former was $2.3 \mathrm{yr}$ (range two months -8 yr). Five had pericardial effusions. ${ }^{10}$ All had weakness confirmed by quadriceps force measurements. ${ }^{11}$ One patient had Hoffman's syndrome with large calves and quadriceps (patient 1), two had reduced muscle bulk (patients 3 and 9), and the remainder had normal muscle bulk on clinical examination.

\section{MATERIAL AND METHODS}

Patients gave informed verbal consent for the investigations and additional written consent for needle biopsy. In each patient the quadriceps maximum voluntary contraction was determined and compared with the lower limit of normal for normal subjects of the same body weight. Blood was taken for plasma creatine kinase (CK) activity on two or more occasions prior to strength testing and measured on unhaemolysed blood at $37^{\circ} \mathrm{C}$ using Boehringer kits. In the two patients with markedly raised plasma $C K$ activities the cardiac and skeletal muscle isoenzymes were calculated and it was shown that skeletal mus- cle was the main source for the raised total CK activity. Conventional needle electromyography (Disa Type 13K 53) of the quadriceps was performed on each patient and evidence of myopathy, chronic par-

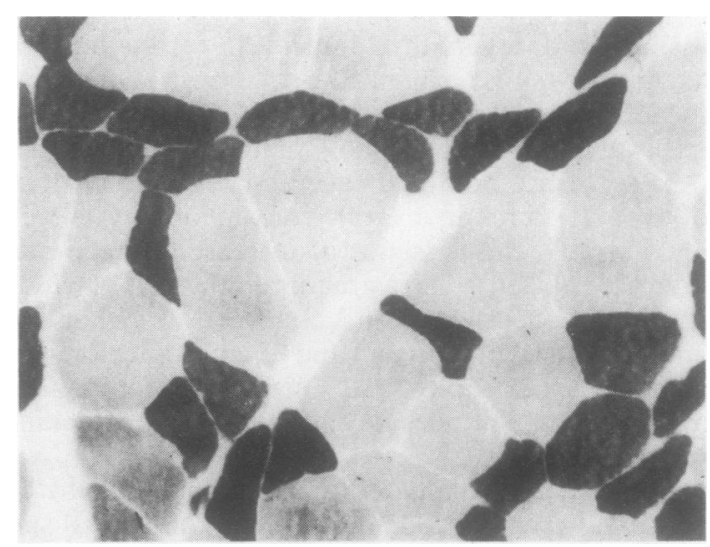

Fig. 1 Characteristic type II fibre atrophy (dark staining fibres) shown on ATPase stain of left vastus lateralis. 

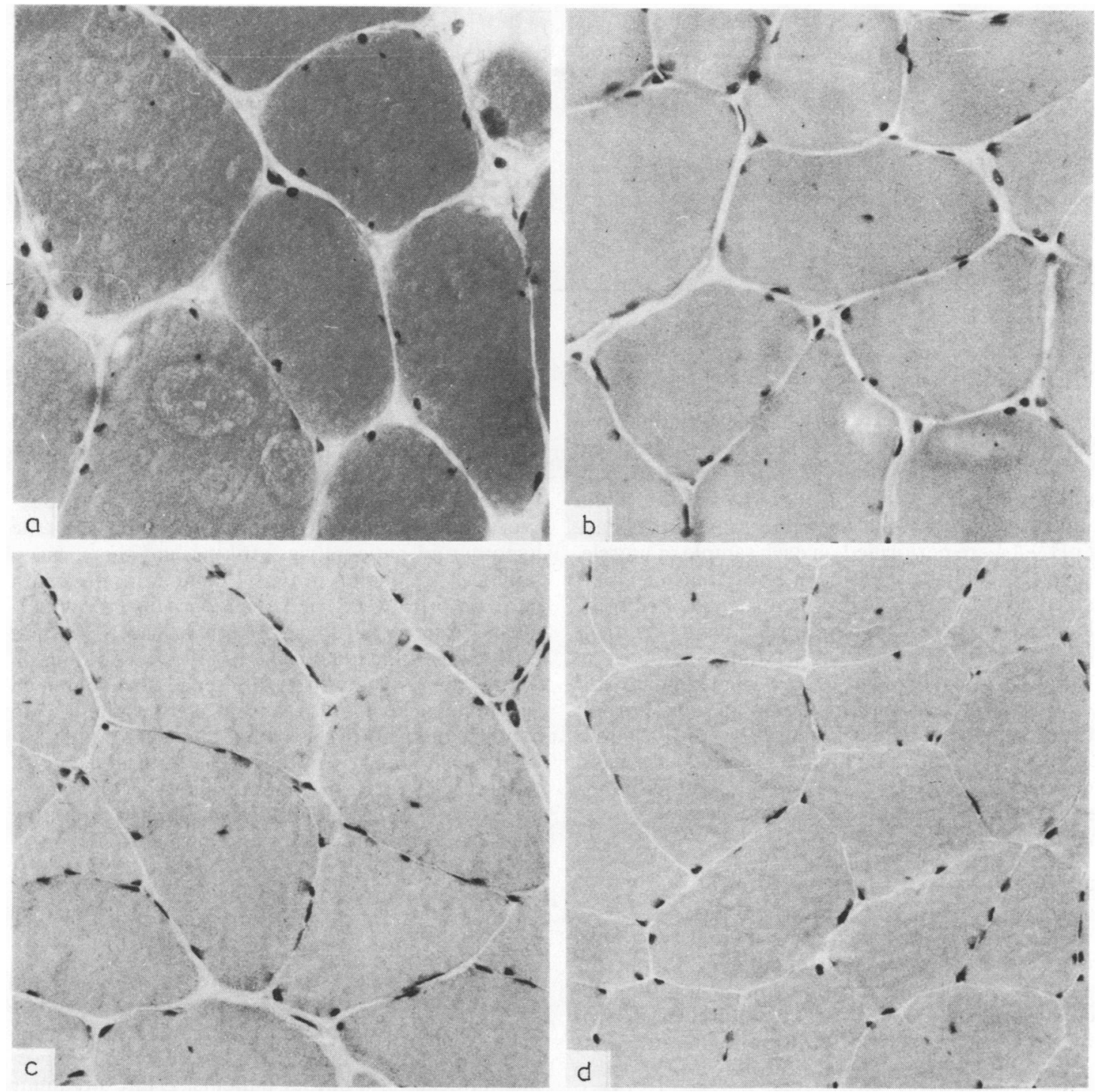

Fig. 2 Quadriceps biopsies. Haematoxylin and eosin stain. Magnification $\times 250$. Progressive reduction in the size of large fibres (shown to be type I fibres on a separate ATPase stain) and reduction of increased internal nuclei on serial biopsies of the left quadriceps. Persistent abnormalities remain on the final biopsy including occasional internal nuclei and variation in fibre size. The dates of the biopsies were (a) 30.1.1981 the day prior to thyroxine replacement; (b) 1.4.1981 when the patient was still biochemically hypothyroid; (c) 7.7.1981 when biochemically euthyroid for seven weeks and (d) 1.3.1982 when biochemically euthyroid for nine months (thirteen months therapy).

tial denervation and myotonia was sought. Brief, small amplitude and frequently polyphasic motor units, and a reduced overall amplitude of the signal on moderate volition was taken as evidence of myopathic process. Where indicated other muscles were sampled for evidence of denervation.

Vastus lateralis muscle was sampled under local anaesthesia. ${ }^{12}$ All 11 patients were biopsied prior to treatment and eight were rebiopsied after a mean period of 9.2 months of treatment with 1 -thyroxine (range 5.3-13.3 months) and when continuously biochemically euthyroid for a mean period of 4.9 months (range 2-11 months). Care was taken that the site of the second biopsy was taken well away 

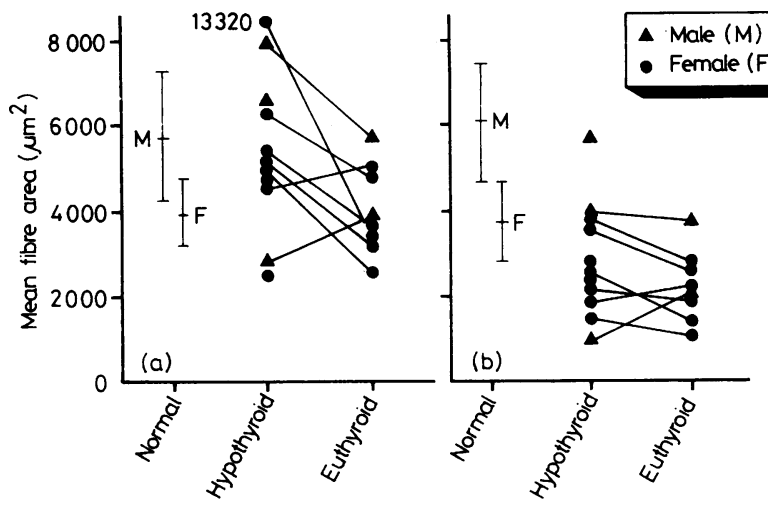

from the original biopsy. In two patients serial biopsies were performed and of these one patient also had his calf muscles serially biopsied. Haematoxylin and eosin stains, stains for NADH, tetrazolium reductase, acid phosphatase and for myosin ATPase at pH 9.4 were performed on each sample of muscle. Using the ATPase stain mean fibre areas of type I and type II fibres were obtained by electronic planimetry. ${ }^{9}$ Biopsies were reported by Professor JF Smith and Dr JM Round. A separate small portion of muscle (less than $50 \mathrm{mg}$ ) was studied for mitochondrial function. ${ }^{2}$ In addition a small portion of muscle was examined for ultrastructural characteristics. ${ }^{13}$ Student's unpaired and paired $t$ tests and the Wilcoxon paired sign tests were used for analysing the significance of mean fibre area measurements.

\section{Results}

Table 1 shows that a raised plasma $\mathrm{CK}$ activity and a myopathic EMG were common findings. In patients 1 and 3 the plasma creatine kinase was high at activities usually associated with muscular dystrophy. In every instance it fell to normal with treatment. Both patients 4 and 11 had a myopathic EMG, sampling the quadriceps muscle, despite a normal needle biopsy on light microscopy.

\section{VASTUS LATERALIS NEEDLE BIOPSY FINDINGS Light microscopy}

Table 2 outlines the histological findings and mean fibre areas of type I and type II fibres in our hypothyroid patients compared to normal subjects. Abnormalities on biopsy were common and persisted in a substantial proportion of the same patients when euthyroid, though considerable improvement had often occurred. Fig. 1 shows the characteristic type II fibre atrophy. Fig. 2 shows fibre enlargement (identified on an ATPase stain as type I fibres) with progressive reduction in the size of these fibres on serial biopsies, and increased internal nuclei. Many abnormalities still persisted after patient 1 had been euthyroid for nine months.

The characteristic type II mean fibre area reduction and increased type I fibre area in the hypothyroid patients was striking and there was a significant reduction in type I mean fibre area with treatment $(\mathrm{p}<0.05)$ and a tendency also for type II mean fibre area to reduce but this was not significant $(p>0.05)$. Individual changes are shown in Fig. 3 . There was also very little difference between mean and median fibre areas, and in eight patients with hypothyroidism (five women and three men) in whom histograms were available for frequency of different fibre area size, the median type I fibre area averaged $6484 \mu \mathrm{m}^{2}$ against a type I mean fibre area of $6760 \mu \mathrm{m}^{2}$. The corresponding median type II fibre area averaged $3510 \mu \mathrm{m}^{2}$ compared to a type II mean fibre area of $3580 \mu \mathrm{m}^{2}$.

\section{Ultrastructural changes}

Of eight suitable specimens in the hypothyroid group all showed abnormalities including myofilament loss with the accumulation of glycogen in seven patients, increased vacuoles in all, abnormal mitochondria in four patients, $\mathrm{Z}$ line streaming in six and increased lysosomes and lipofuscin pigment in four patients. Fig. 4 shows characteristic o abnormalities. With treatment there was improve- $N$ ment in the pathological changes. Of six suitable $N$ specimens in this euthyroid group the only persisting abnormalities were increased lipofuscin pigment in four patients, increased vacuoles in one patient and increased glycogen in one other.

\section{Fibre percentages and mitochondrial enzyme activities}

Table 3 shows that no change occurred in the fibre percentages with treatment and that these were in the middle of the normal range. The mitochondrial 

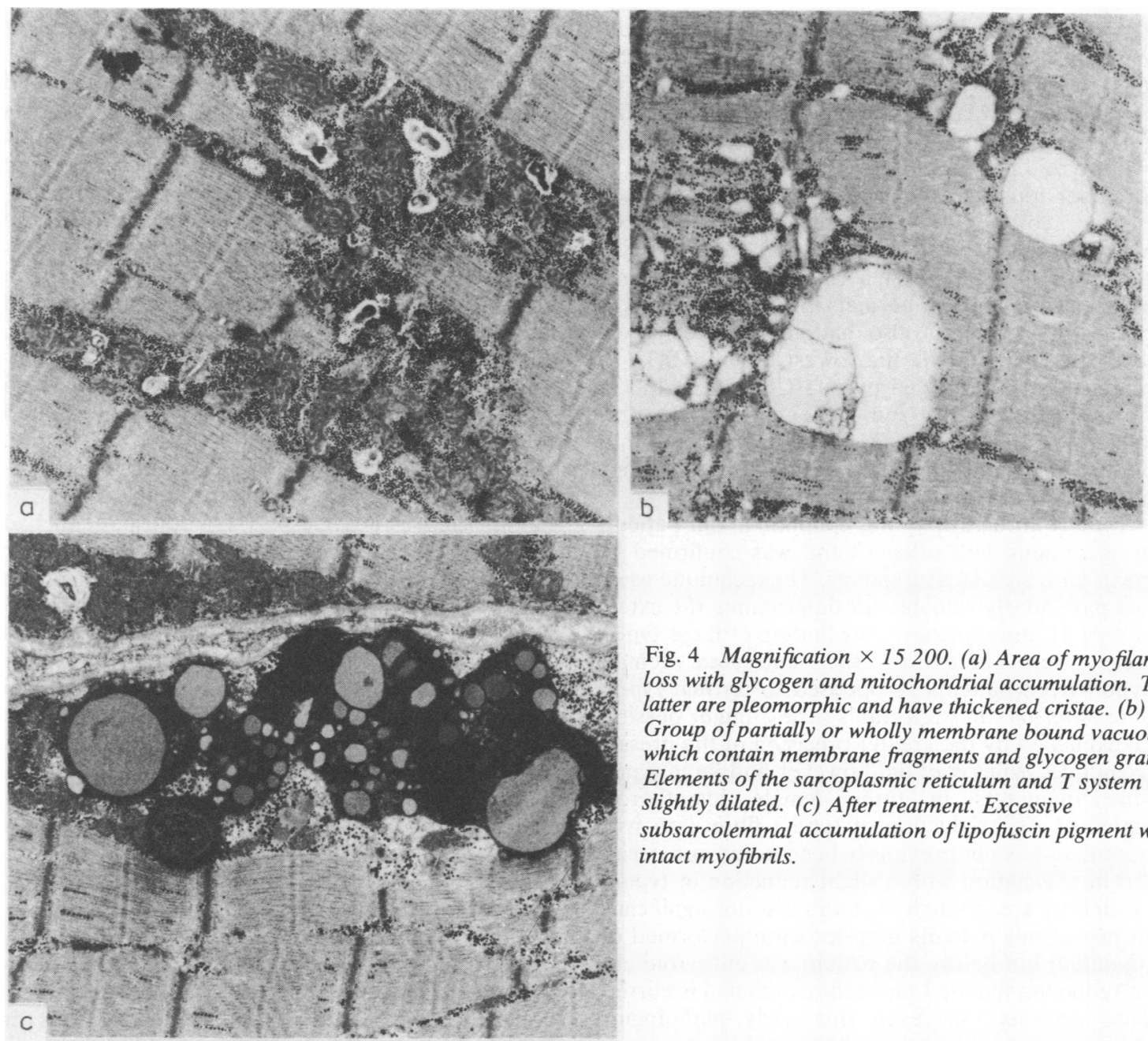

Fig. 4 Magnification $\times 15$ 200. (a) Area of myofilament loss with glycogen and mitochondrial accumulation. The latter are pleomorphic and have thickened cristae. (b) Group of partially or wholly membrane bound vacuoles which contain membrane fragments and glycogen granules. Elements of the sarcoplasmic reticulum and T system are slightly dilated. (c) After treatment. Excessive

subsarcolemmal accumulation of lipofuscin pigment with intact myofibrils.

Table 3 Effects of treatment on fibre percentages and mitochondrial enzyme activities on vastus lateralis needle biopsy in hypothyroidism

\begin{tabular}{|c|c|c|c|c|c|c|}
\hline \multirow[t]{2}{*}{ Fibre percentages } & \multirow{2}{*}{\multicolumn{2}{|c|}{$\begin{array}{l}\text { Controls } \\
\text { Range }\end{array}$}} & \multicolumn{2}{|c|}{ Hypothyroid $(n=11)$} & \multicolumn{2}{|c|}{ Euthyroid $(n=8)$} \\
\hline & & & Mean & (Range) & Mean & (Range) \\
\hline $\begin{array}{l}\text { Type I fibres } \\
\text { Type II fibres }\end{array}$ & $\begin{array}{l}20-80 \\
20-80\end{array}$ & & $\begin{array}{l}48 \% \\
52 \%\end{array}$ & $\begin{array}{l}(20-80 \%) \\
(20-69 \%)\end{array}$ & $\begin{array}{l}53 \% \\
47 \%\end{array}$ & $\begin{array}{l}(31-73 \%) \\
27-69 \%)\end{array}$ \\
\hline $\begin{array}{l}\text { Enzyme activity ( } \mu \mathrm{mol} / \mathrm{g} / \mathrm{min}) 37^{\circ} \mathrm{C} \\
\text { (Pyruvate }+ \text { malate) cytochrome reductase } \\
\text { (Palmityl carnitine }+ \text { malate) cytochrome reductase } \\
\alpha \text { oxoglutarate cytochrome reductase } \\
\text { Succinate cytochrome reductase } \\
\text { Cytochrome oxidase }\end{array}$ & $\begin{array}{l}1.25 \\
0.7 \\
1.5 \\
3.2 \\
21.7\end{array}$ & $\begin{array}{rl}(0.4-2 \cdot 9 & n=5 \\
0.2-1 \cdot 5 & n=5 \\
0.3-2 \cdot 3 & n=5 \\
1 \cdot 2-4 \cdot 7 & n=3 \\
(6.8-37.0) & n=6\end{array}$ & $\begin{array}{l}0.45 \\
0.25 \\
0.33 \\
1 \cdot 16 \\
8 \cdot 12\end{array}$ & 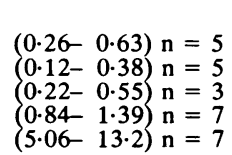 & $\begin{array}{l}\text { ND } \\
\text { ND } \\
\text { ND } \\
\text { ND } \\
7 \cdot 8(4\end{array}$ & 8) $n=5$ \\
\hline
\end{tabular}

ND $=$ not done.

enzyme activities tended to be at the lower end of the normal range for all the enzymes measured in the hypothyroid patients and no significant change occurred in the levels of the cytochrome oxidase enzyme activities with treatment.

\section{Discussion}

Our study showed that weak patients with hypothyroidism had abnormalities on needle biopsy of skeletal muscle or on EMG or both. Not all 
hypothyroid patients however are weak. Indeed, Wiles et al, using the same force measuring equipment, found only two of their eight hypothyroid patients were weak. During submaximal isometric quadriceps contractions held to fatigue, their hypothyroid patients sustained comparable levels of force for longer than normal subjects at reduced energy cost. ${ }^{8}$ Our patients had advanced hypothyroidism both clinically and biochemically and associated high plasma CK activities. The only patient with both a normal EMG and a needle biopsy in this series also had the highest serum thyroxine $(63 \mathrm{nmol} / \mathrm{l})$ the lowest serum TSH (15 IU/l) and also a normal plasma CK (54 IU/l). On symptomatic enquiry our patients had had prolonged hypothyroidism at presentation and thus both severity and chronicity might explain the high incidence of myopathy in our series.

Type II fibre atrophy was common in our patients in agreement with others ${ }^{38}$ and was confirmed by mean fibre area measurements. The technique used ${ }^{9}$ was particularly valuable for determining the extent of type II fibre atrophy. Our finding of large type I mean fibre areas in the untreated female hypothyroid patients as opposed to normal type I fibre diameters in McKeran's series ${ }^{3}$ might possibly be explained by the greater precision of the present technique. Wiles et al did however find large type I fibre diameters in three female hypothyroid patients. ${ }^{8}$ The reduction of type I fibre area with treatment has not previously been noted and occurred in association with a slight reduction in type II mean fibre area though the latter was not significant. In two of our patients biopsies were performed on treatment but before the patient was euthyroid and no reduction in type I mean fibre area had occurred. This suggests that even this early pathological change is slow compared to the rapid improvement in the raised plasma creatine kinase, low urinary 3 methylhistidine excretion and prolonged ankle jerk relaxation time in treated hypothyroidism. ${ }^{23}$ One possible explanation for the type I mean fibre area enlargement in hypothyroidism is a compensatory mechanism on the part of skeletal muscle to the type II fibre atrophy. Certainly in the two patients with the most severe fibre atrophy (patients 1 and 2) the type I mean fibre areas were the largest. However in other conditions associated with type II fibre atrophy such as steroid myopathy ${ }^{14}$ type I mean fibre areas are small. ${ }^{15}$ Furthermore in hypothyroid patients treatment caused a reduction in type I mean fibre area in the majority $(p<0.05)$ with a reduction rather than an increase in the type II mean fibre area. In fact the failure of type II mean fibre areas to attain normal levels probably represents the early timing of our biopsies and others have shown that fibre atrophy may be corrected with treatment $\frac{\stackrel{0}{*}}{\vec{*}}$ though fibre loss is slower to recover. ${ }^{8}$

Our findings coincide with McKeran's who found that the most severely clinically affected patients tended to have biopsy abnormalities like fibre atrophy and that the most severe changes were not $\frac{\bar{D}}{\bar{D}}$

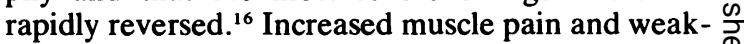
ness rarely accompany thyroxine therapy. ${ }^{17}$ The $\mathscr{\Phi}$ biopsies in patients 1 and 3 after substantial periods of treatment are still grossly abnormal though in $\overrightarrow{0}$ patient 1 the quadriceps biopsy is much improved compared to the calf which has shown little change. $\vec{\omega}$ It is surprising that despite markedly different clini- $\frac{\Omega}{2}$ cal presentations the pathological pictures are so? similar in these two patients. Patient 1 had increased $\omega$ muscle bulk (confirmed by CT scanning), ir bradykinesia and the picture of Hoffman's syn- $r$ drome $^{18}$ but patient 3 had reduced bulk and proxi- $\overrightarrow{0}$ mal muscle wasting. Despite this both patients had huge type I mean fibre areas $\left(7900+13330 \mu \mathrm{m}^{2}\right)$. A marked normal variation in fibre percentage occurs, ${ }^{9}$ but in patient 3 who had only $20 \%$ type II fibres, the fibre loss probably explains the clinical $\vec{\oplus}$ differences. Thus despite hypertrophied type I fibres $\stackrel{\infty}{\omega}$ the type II fibre loss resulted in reduced bulk. In 0 patient 1 however, despite type II fibre atrophy, no fibre loss occurred and the markedly hypertrophied type I fibres produced the picture of increased bulk. With treatment an increase in force was demons- $\frac{\propto}{\Phi}$ trated despite a reduction in muscle bulk, confirmed $\stackrel{2}{\rightarrow}$ on CT scanning.

The frequency of abnormalities on electronmic- $-\frac{3}{3}$ roscopy of vastus lateralis in our hypothyroid patients was impressive, including patient 4 whose biopsy on light microscopy was normal. Honey-? combing of mitochondria, the presence of vacuola- $-\frac{0}{3}$ tion, a dense matrix and lipid inclusions in mitochondria have all been described. ${ }^{6719}$

In the present series abnormal mitochondria were often seen in association with glycogen inclusions in focal or widespread areas of myofilament loss. Others have related the presence of glycogen inclusions in muscle fibres to the clinical severity of the myxoedema. ${ }^{5}$ It has been attributed to diminished enzyme activity in glycogen metabolism in $\tilde{O}$ hypothyroidism. ${ }^{6}$ Low fasting blood glucose con- N centrations in the early morning in hypothyroido myopathy and the failure of lactate to rise aftero forearm ischaemia supports this idea. ${ }^{20}$ These inclusions are not always rapidly lost when treatment is $\stackrel{?}{+}$ started. ${ }^{16}$

Mitochondrial enzyme activities were at the lower end of the normal range with normal ratios of cytochrome oxidase to succinate cytochrome reductase $\frac{\mathbb{Q}}{\Omega}$ implying functionally normal but reduced numberso of mitochondria. These low activities occurred 
despite an increase in type I fibre area, and as type I fibres are usually rich in oxidative enzymes, it is possible this reduction in activity was due to hypothyroidism directly or indirectly by inactivity. Although no change in the activities occurred with treatment, a marked reduction in type I area was observed and so in proportion to the area of type I fibres present, activities actually rose. Before rapid erroneous interpretations are made however, more information about the influence of activity and inactivity on these mitochondrial enzymes is needed and this is at present being studied. The technique does appear a promising one for correlating structure, function and metabolism at the cellular level and possibly also the effects of treatment.

Although it is well known that the plasma CK may be raised in hypothyroidism ${ }^{21}$ striking increases as in patients 1 and 3 are not so well known ${ }^{22}$ and may suggest coexisting muscular dystrophy to the unwary, particularly in patient 1 with calf hypertrophy and proximal weakness. McKeran comments on the biochemical severity of hypothyroidism correlating with the frequency of pathological changes in muscle. ${ }^{16}$ In our series all but patient 4 with a raised plasma CK had associated structural changes. Our patients had had long-standing symptomatic evidence of hypothyroidism and chronicity as well as biochemical severity might have been equally important in the genesis of these changes. In every patient the plasma CK activity fell rapidly with treatment to normal before any increase in strength or structural change occurred ${ }^{23}$ and others have commented on the mechanisms including changes in capillary permeability. ${ }^{24}$

In summary when force measurements confirm the existence of muscle weakness in hypothyroidism there is often pathological, electromyographic and biochemical evidence of myopathy. Type II fibre atrophy, reduction in type II and an increase in type I mean fibre area and a reduction in the latter with treatment are the principal findings of this study as are ultrastructural and mitochondrial function abnormalities. The severity of the pathological changes may be related to chronicity and severity of hypothyroidism and the time course of recovery of the pathological changes is often slow and possibly incomplete in severe cases. Further research should focus on the mechanisms underlying type II fibre atrophy and the regulation of type I fibre size in untreated and treated hypothyroidism.

We gratefully acknowledge the help of Sister Jones and the nursing staff of The Charles Dent Metabolic Unit and our clinical colleagues for referring patients; Professor JF Smith kindly reported on the biopsies, Dr Kerry Mills performed all the elec- tromyograms and gave considerable expert advice. Miss V Patel and Miss D Pain helped in the preparation of the sections and Dr J McDougall gave expert advice on the ultrastructural findings. This work was supported by the Wellcome Trust and the Muscular Dystrophy Group of Great Britain.

\section{References}

' Edwards RHT. Percutaneous needle biopsy of skeletal muscle in diagnosis and research. Lancet 1971;ii:593-6.

${ }^{2}$ Gohil K, Jones DA, Edwards RHT. Analysis of mitochondrial function with techniques applicable to needle biopsy specimens. Clin Physiol 1982;1:195-207.

${ }^{3}$ McKeran RO, Slavin G, Andrews TM, Ward P, Mair WGP. Muscle fibre type changes in hypothyroid myopathy. J Clin Pathol 1975;28:659-63.

${ }^{4}$ McKeran RO, Ward P, Slavin G, Paul EA. Central nuclear counts in muscle fibres before and during treatment in hypothyroid myopathy. J. Clin Pathol 1979;32:229-33.

s Aström KE, Kugelberg E, Muller R. Hypothyroid myopathy. Arch Neurol 1961;5:472.

- Norris FH, Panner BJ. Hypothyroid myopathy. Clinical, electromyographical and ultrastructural observations. Arch Neurol 1966;14:574.

' Gustafsson R, Tatt JR, Lindberg O, Ernster L. The relationships between the structure and activity of rat skeletal muscle mitochondria after thyroidectomy and thyroid hormone replacement. J Cell Biol 1965;26:555.

- Wiles CM, Young A, Jones DA, Edwards RHT. Muscle relaxation rate, fibre type composition and energy turnover in hyperand hypothyroid patients. Clin Sci 1979;57:375-84.

9 Round JM, Jones DA, Edwards RHT. A flexible microprocessor system for the measurement of cell size. J Clin Pathol 1982;35:620-4.

${ }^{10}$ Khaleeli AA, Memon N. Factors affecting resolution of pericardial effusions in primary hypothyroidism. A clinical, biochemical and echocardiographic study. Postgrad Med J 1982; 58:21-4.

"Edwards RHT, Young A, Hosking GP, Jones DA. Human skeletal muscle function: description of tests and normal values. Clin Sci. 1977;52:283-90.

${ }^{12}$ Edwards RHT, Young A, Wiles CM. Needle biopsy of skeletal muscle in the diagnosis of myopathy and the clinical study of muscle function and repair. $N$ Engl J Med 1980;302:261-71.

${ }^{13}$ McDougall J, Wiles CM, Edwards RHT. Spiral membrane cylinders in the skeletal muscle of a patient with melorheostosis. Neuropathol Appl Neurobiol 1980;6:69-74.

${ }^{14}$ Satayoshi E, Kinoshita M. Some aspects of thyrotoxic and steroid myopathy. Walton JM, Canal N, Scarlato G, eds. Muscle diseases Proceedings of an International Congress, Milan. Amsterdam: Excerpta Medica, 1969:455-63.

15 Khaleeli AA, Edwards RHT, Gohil K, et al. Corticosteroid myopathy. A clinical and pathological study. Clin Endocrinol 1983;18:155-66.

${ }^{16}$ McKeran RO, Slavin G, Ward P, Paul E, Mair WGP. Hypothyroid Myopathy. A clinical and pathological study. $J$ Pathol 1980;132:35-54.

${ }^{17}$ Fessel WJ. Myopathy of hypothyroidism. Ann Rheum Dis 1968;27:590.

${ }^{18}$ Klein I, Parker M, Sherbert R, Ayyar DR, Levey GS. Hypothyroidism presenting as muscle stiffness and pseudohypertrophy: Hoffman's syndrome. Am J Med 1981;70:891-5.

19 Godet-Guillain J, Fardeau M. Hypothyroid myopathy. Histological and ultrastructural study of an atrophic form. Walton JN, 
Canal N, Scarlato G, eds. Muscle diseases Proceedings of an International Congress, Milan. Amsterdam: Excerpta Medica, 1970:512.

${ }^{20}$ McDaniel HG, Pittman CS, Oh SJ, Di Mauro S. Carbohydrate metabolism in hypothyroid myopathy. Metabolism 1977; 26:867.

${ }^{21}$ Graig FA, Smith JC. Serum creatine phosphokinase in altered thyroid states. J Clin Endocrinol 1965;25:723-31.

${ }^{22}$ Goldmann J, Matz MD, Mortimer R, Freeman R. High elevations of creatine phosphokinase in hypothyroidism. An isoenzyme analysis. JAMA 1977;238:325-6.

${ }^{23}$ Khaleeli AA, Round JM, Rennie MJ, Edwards RHT. Effects of treatment on muscle structure and function in hypothyroid myopathy. Eur Soc Clin Invest 1982;12:19.

${ }^{24}$ Doran RD, Wilkinson JH. The origin of the elevated activities of creatine kinase and other enzymes in the sera of patients with myxoedema. Clin Chim Acta 1975;62:203.

Requests for reprints to: Dr AA Khaleeli, Department of Medicine, University College London, School of Medicine, London WC1E 6JJ, England. 